\title{
Is inhaled nitric oxide a miraculous molecule? The analysis of nitric oxide use in newborns with persistent pulmonary hypertension of the newborn
}

\author{
SRNKOVA Patricia ${ }^{1 *}$, BRUCKNEROVA Jana ${ }^{1 *}$, BRUCKNEROVA Ingrid ${ }^{2 *}$ \\ Neonatal Department of Intensive Medicine Faculty of Medicine, Comenius University in Bratislava and National \\ Institute of Children’s Diseases, Bratislava, Slovakia. ingrid.brucknerova@fmed.uniba.sk
}

\begin{abstract}
AIM: The aim of this study was to establish a set of hospitalised patients with persistent pulmonary hypertension of the newborn (PPHN) by using retrospective analysis according to gestational age, position during childbirth, type of childbirth, dosage and length of the treatment by inhaled nitric oxide (NO) and application of inotropic agents as well as interindividual specifics and the background of PPHN.

RESULTS: Our cohort consisted of 11 newborns who were hospitalised in Neonatal Department of Intensive Medicine between 1st January 2017 and 31st December 2019. Four of these patients were born prematurely. Only two out of eleven patients were born vaginally. Nine of the newborns were diagnosed with secondary $\mathrm{PPHN}$, in three of these cases it was caused by infection. The highest dose of inhaled nitric oxide used was $40 \mathrm{ppm}$.

CONCLUSION: The focus of this paper was the therapeutic use of nitric oxide, its various applications and the effect of it on pulmonary circulation of the newborn. Inhaled NO is a selective pulmonary vasodilator used as a therapeutic agent for PPHN of the newborn. The conclusions of this paper can be beneficial in the development of better therapeutic strategies for patients with PPHN in the future (Tab. 3, Fig. 1, Ref. 40). Text in PDF www.elis.sk KEY WORDS: newborn, nitric oxide, persistent pulmonary hypertension of the newborn, inhaled nitric oxide.
\end{abstract}

\begin{abstract}
Abbreviations: cGMP - cyclic guanosine monophosphate, ECMO - extracorporeal membrane oxygenation, iNO - inhaled nitric oxide, NDIM - Neonatal Department of Intensive Medicine, NO nitric oxide, PDE3 - phosphodiesterase type 3, PH - pulmonary hypertension, PPHN - pulmonary hypertension of the newborn, PVR - pulmonary vascular resistance
\end{abstract}

\section{Introduction}

In small quantities, nitric oxide (NO) is a part of physiological processes as a signal molecule. These include regulation of blood flow (vasodilation), thrombocyte reactivity and neurotransmission. Higher concentration of NO has cytotoxic and cytostatic properties $(1,2)$. There is growing evidence that NO has an important role in the regulation of pulmonary function and pathophysiology of pulmonary diseases $(3,4)$. NO was detected in higher concentra-

${ }^{1}$ Faculty of Medicine, Comenius University in Bratislava, Slovakia, and ${ }^{2}$ Neonatal Department of Intensive Medicine Faculty of Medicine, Comenius University in Bratislava and National Institute of Children's Diseases, Bratislava, Slovakia

Address for correspondence: I. Brucknerova, MD, PhD, Prof, Faculty of Medicine, Comenius University in Bratislava, NUDCH, Limbova 1, SK-833 40 Bratislava, Slovakia.

Phone: +421.2 .59371232$

"These authors contributed equally to the text. tion in exhaled air of animals and people with various inflammatory diseases of the pulmonary system $(5,6)$.

The use of inhaled nitric oxide (iNO) to treat newborns with hypoxic respiratory failure associated with pulmonary hypertension $(\mathrm{PH})$ was approved by the European Medicines Agency and Food and Drug Administration at the beginning of the 21 st century due to numerous studies which demonstrated that treatment with iNO reduces the use of the extracorporeal membrane oxygenation (ECMO) in term and preterm babies (7).

Twenty years later, iNO is used for hypoxic respiratory failure in newborns with different aetiologies (8). In Slovakia, iNO is only used in patients with persistent pulmonary hypertension of the newborn (PPHN). The ability to influence pulmonary vascular tone without a decrease in systematic vascular tone is the reason why iNO is preferred in the treatment of PPHN (9). PPHN is a complex disease that can occur within a wide range of cardiopulmonary disorders, which are characterized by $\mathrm{PH}$ and altered vasoreactivity. It can lead to complications such as chronic lung disease, delayed psychomotor development and death $(9,10,11)$. The main characteristic of these disorders is increased pulmonary vascular resistance (PVR) which causes right-to-left shunting of blood through the arterial duct and/or foramen ovale. The quick improvement in oxygenation after therapy with iNO is a result of selective decrease in PVR which leads to less mixing of venous and arterial blood through the shunts. Nonetheless, the oxy- 


\section{3-159}

genation can also improve in patients without right-to-left shunts $(12,13,14)$.

When inhaled, NO binds to haemoglobin which is saturated with oxygen to $60-100 \%$ in capillaries. If the saturation of haemoglobin is lower, NO is binding to deoxyhaemoglobin and creates nitrosylhaemoglobin which in the presence of oxygen changes to nitric oxides and methaemoglobin (15).

Methaemoglobin is toxic because it is unable to bind and release oxygen from the molecule. High concentration of methaemo globin has a negative effect on oxygen transport in the body (16). In newborns, the activity of methaemoglobin reductase is lowered compared to adults (17). It is advised to check the levels of methaemoglobin in the blood one hour after starting the therapy by spectrophotometric analyser, which is capable of distinguishing foetal haemoglobin from methaemoglobin. The physiological amount of methaemoglobin in blood is under $2 \%$. When the amount is higher, it is important to lower the dose of iNO or completely stop the administration of iNO. There is also the possibility to administer methylene blue to reduce methaemoglobin in circulation $(15,18)$.

The iNO is recommended for use for infants after 34 weeks of gestation with hypoxaemic respiratory failure associated with $\mathrm{PH}$ who have insufficient response to mechanical ventilation. The maximal starting dose is $20 \mathrm{ppm}$. It is important to observe preductal and postductal saturations if the gap is higher than $10 \%$, it means a significant right to left shunting is present. It is recommended to use high-frequency oscillatory ventilation if possible and also administer surfactant. It is important to rule out any congenital heart disease with an echocardiogram exam. Weaning of the therapy needs to be done cautiously because rebound $\mathrm{PH}$ can occur $(9,15,19)$.

During the foetal period, foetal circulation has a high PVR because the lungs are not ventilated. The systemic vascular resistance in foetal circulation is lower than PVR because the placenta acts as a reservoir of blood. Gradient between systemic and pulmonary resistance is the reason why there is right-to-left shunting of blood through ductus arteriosus to be oxygenated in placenta $(20,21)$.

After being born and taking the first breath, the PVR quickly decreases due to distension of the lungs and endogenous chemical vasodilators such as prostaglandins and NO. Production of NO starts during birth and after birth, it is enhanced by the shear stress and the concentration of oxygen in the blood activates the enzyme endothelial NO-synthase which also helps with vasodilation after birth (22).

If the PVR remains high after birth, a resistance gradient like the one in foetal circulation causes right-to-left shunt of blood across the open ductus arteriosus. Therefore, some amount of blood is bypassing the pulmonary circulation without being oxygenated which leads to cyanosis. This is the basis for PPHN (11, 21).

Risk factors for PPHN include structural lung abnormalities caused by congenital diaphragmatic hernia $(23,24,25)$. An American study which involved 12,000 newborns showed a 5-fold increase in the incidence of PPHN in neonates born by Caesarean section compared to those born vaginally. From the same study, also chorioamnionitis emerged as a significant risk factor, increasing the risk of PPHN three times $(23,26)$.

PPHN is most commonly diagnosed in term newborns but can also occur in premature infants. PPHN is manifested by respiratory failure and cyanosis, which occurs 6-12 hours after birth. Laboratory values for PPHN include hypoglycaemia, hypocalcaemia, polycythaemia, and thrombocytopaenia (12). Hypocalcaemia affects the functioning of endothelial NO-synthase, so its correction is important. The X-ray of the thorax finding is variable and depends on the primary disease associated with PPHN. In idiopathic PPHN, an X-ray shows reduced lung blood flow with mild hyperinflation without parenchymal infiltrations (22).

On echocardiography, we need to rule out other causes of hypoxaemia, such as structural changes in the heart. Although high pressure in the pulmonary arteries is a common finding in neonatal lung diseases, the diagnosis of PPHN is unclear until we have clear evidence of a bidirectional or dominant right-left shunt through the ductus arteriosus patens or foramen ovale apertum (27).

The management of a newborn with PPHN includes the treatment and prevention of hypothermia, hypoglycaemia, hypoxaemia, hypocalcaemia, anaemia, metabolic acidosis, infectious complications and hypovolemia. Proper nutrition, optimal ambient temperature, minimizing stress stimuli and, if necessary, administering analgesics and sedation $(22,27)$.

Less severe PPHN with minimal respiratory distress can be detected at screening for cardiac developmental defects after birth if a baby develops reduced oxygen saturation (28). The therapy in these newborns consists of supportive therapy and administration of oxygen. It is important that they are closely monitored for the risk of sudden deterioration of the disease and the need for administration of non-invasive ventilation or intubation (22). It is important to set the ventilation parameters to achieve an "ideal" ventilation volume, because both low and high ventilation volumes increase PVR. Adequate ventilation volume also prevents high pressure lung trauma. Lung tissue damage can lead to pulmonary oedema, decreased pulmonary compliance and increased sensitivity of lung tissue to inflammation due to increased cytokine production and neutrophil accumulation in the lungs $(27,29)$.

Today, PPHN therapy involves improving systemic haemodynamics by fluid repletion and cardiotonic therapy (dobutamine, dopamine), which has a positive effect on cardiac output and oxygen transport to the body. If there is no response to this therapy, ECMO is often required (30).

Low dose iNO therapy (5-20 ppm) improves oxygenation and reduces the need for ECMO in patients with various aetiologies of PPHN $(13,31)$. During the treatment, it is important to monitor the patient's oxygenation parameters and gradually reduce the dose of iNO as they improve. Discontinuation of iNO is possible only after a significant reduction in the patient's ventilatory support or after 96 hours of therapy. If we decide to stop the therapy, it is necessary to reduce the dose to $1 \mathrm{ppm}$ for 30-60 minutes and then stop the administration of $\mathrm{iNO}$ and watch for signs of hypoxia in the newborns. If saturation drops by more than $20 \%$, therapy should be resumed at $5 \mathrm{ppm}$ and the decision to discontinue therapy should be considered after 12 to 24 hours (15). 
Milrinone and sildenafil are vasodilators which are used in severe iNO therapy resistant cases of PPHN. Milrinone inhibits cyclic guanosine monophosphate (cGMP) by degrading cGMPspecific phosphodiesterase type 5 and sildenafil inhibits cyclic adenosine monophosphate by degrading phosphodiesterase type 3 (PDE3) (32). Sildenafil administered orally in children with PPHN improved oxygenation and reduced mortality in studies in which iNO was not available (33). Intravenous administration of sildenafil, according to a study by Steinhorn et al, improves oxygenation in patients without prior iNO therapy (21). When administered systemically, there is a high risk of side effects such as hypotension due to systemic vasodilation. This risk can be reduced by slow intravenous administration of an initial dose ( $0.4 \mathrm{mg}$ over 3 hours) followed by a maintenance dose $(0.07 \mathrm{mg} /$ $\mathrm{kg} / \mathrm{h}$ ). Administration of sildenafil reduces the intensity of the rebound phenomenon at the end of iNO administration (32).

\section{Methods}

data was collected from records of patients who were hospitalized at Neonatal Department of Intensive Medicine (NDIM) between January 1st, 2017 and December 31 st, 2019 (included). These patients were selected based on the diagnosis of PPHN and therapy with iNO. The following data was collected: gestational age, birth weight and length, pathologies related to amniotic fluid, type of delivery, maximal dose of iNO, oxygenation index and type of PPHN. For growth assessment, we used the Fenton growth chart.

\section{Results}

The data was collected from 11 children. All of these patients were prenatally eutrophic and only $2(18 \%)$ were born vaginally. The rest of the patients were born by Caesarean delivery. Four of the newborns were born prematurely $(36.3 \%)$ and the rest of them (7 patients) were born in term. Four newborns were born without amniotic fluid volume pathology, two had anhydramnion, two had polyhydramnion, two had bloodstained amniotic fluid, and two had greenstained amniotic fluid (Tab. 1). The majority of patients had secondary PPHN. The most common reason was pulmonary hypoplasia, infection and meconium aspiration (Tab. 2).

The maximum dose of iNO used was 40 ppm in two patients (Patient 3; Patient 5). These two patients also had the longest duat delivery. ration of iNO use (Patient 3: 95 hours; Patient 5: 80 hours). Patient oxygenation indices ranged from 19.1 to 103 (Tab. 3). Two patients (patient 3; patient 7) were ventilated in synchronized intermittent mandatory ventilation mode, the other nine were ventilated in high-frequency oscillatory mode. Nine newborns were intubated within 24 hours of birth (patients: 1, 2, 4, 5, 7, 8, 9, 10, 11), four of them immediately after birth (patients: $2,4,8,9$ ). The shortest time to extubating was 82 hours, the longest 550 hours (Patient 6 and Patient 8 respectively). The surfactant was administered to three patients. Of these, one was born in gestational week 33 (Patient 8), one in week 41 (Patient 9) and one in week 42 (Patient 11). Sildenafil was administered to seven patients. Inotropic

Tab. 1. Foetal growth, amniotic fluid and type of delivery in hospitalized patients.

\begin{tabular}{ccccc}
\hline Patient & $\begin{array}{c}\text { Gestational age } \\
\text { (weeks+days) }\end{array}$ & Foetal growth & Amniotic fluid & Type of delivery \\
\hline 1 & $40+0$ & eutrophic & green & Caesarean delivery \\
2 & $33+5$ & eutrophic & anhydramnion & Caesarean delivery \\
3 & $35+0$ & eutrophic & polyhydramnion with blood & Caesarean delivery \\
4 & $37+2$ & eutrophic & anhydramnion with blood & Caesarean delivery \\
5 & $40+0$ & eutrophic & normal & vaginal delivery \\
6 & $38+0$ & eutrophic & normal & Caesarean delivery \\
7 & $34+0$ & eutrophic & normal & Caesarean delivery \\
8 & $32+1$ & eutrophic & polyhydramnion & Caesarean delivery \\
9 & $41+0$ & eutrophic & opalesque & vaginal delivery \\
10 & $38+0$ & eutrophic & normal & Caesarean delivery \\
11 & $41+3$ & eutrophic & green & Caesarean delivery \\
\hline
\end{tabular}

Tab. 2. Number of patients sorted by diagnosis and gestational age

\begin{tabular}{lccc}
\hline Diagnosis & All patients & Birth $\geq 37$ weeks & Birth $<37$ weeks \\
\hline Primary PPHN & 2 & 0 & 2 \\
Secondary PPHN & 9 & 7 & 2 \\
\hline Secondary PPHN due to & & 1 & 0 \\
\hline Sepsis & 1 & 0 & 1 \\
Congenital heart problem & 1 & 2 & 1 \\
Pulmonary hypoplasia & 3 & 2 & 0 \\
Infection & 2 & 2 & 0 \\
Meconium aspiration & 2 & & \\
\hline
\end{tabular}

PPHN - persistent pulmonary hypertension of the newborn

Tab. 3. Specific parameters of therapy.

\begin{tabular}{cccccc}
\hline Patient & $\begin{array}{c}\text { Duration } \\
\text { of therapy } \\
\text { (hours) }\end{array}$ & $\begin{array}{c}\text { Maximal } \\
\text { concentration } \\
\text { of iNO (ppm) }\end{array}$ & Inotropic therapy & $\begin{array}{c}\text { Use of } \\
\text { sildenafil }\end{array}$ & $\begin{array}{c}\text { Oxygenation } \\
\text { index }\end{array}$ \\
\hline 1 & 44 & 20 & DOP, ADR & yes & 28.7 \\
2 & 17 & 20 & DOP, ADR & yes & 60 \\
3 & 95 & 40 & ADR, DOB, NOR & yes & 19.1 \\
4 & 3 & 20 & DOP, ADR, DOB & yes & 103 \\
5 & 80 & 40 & ADR, DOB & yes & 35 \\
6 & 41 & 25 & DOP, ADR, DOB & no & 33.4 \\
7 & 20 & 27 & DOP & no & 25 \\
8 & 73 & 20 & DOP, ADR & yes & 28 \\
9 & 5 & 20 & DOP, ADR, DOB, NOR & no & 32 \\
10 & 21 & 20 & DOP, ADR, NOR & no & 41 \\
11 & 68 & 15 & DOP, ADR, DOB & yes & 33 \\
\hline DOP - dopamine, ADR - adrenaline, DOB - dobutamine, NOR - noradrenaline, iNO - inhaled nitric oxide, \\
ppm - parts per million
\end{tabular}



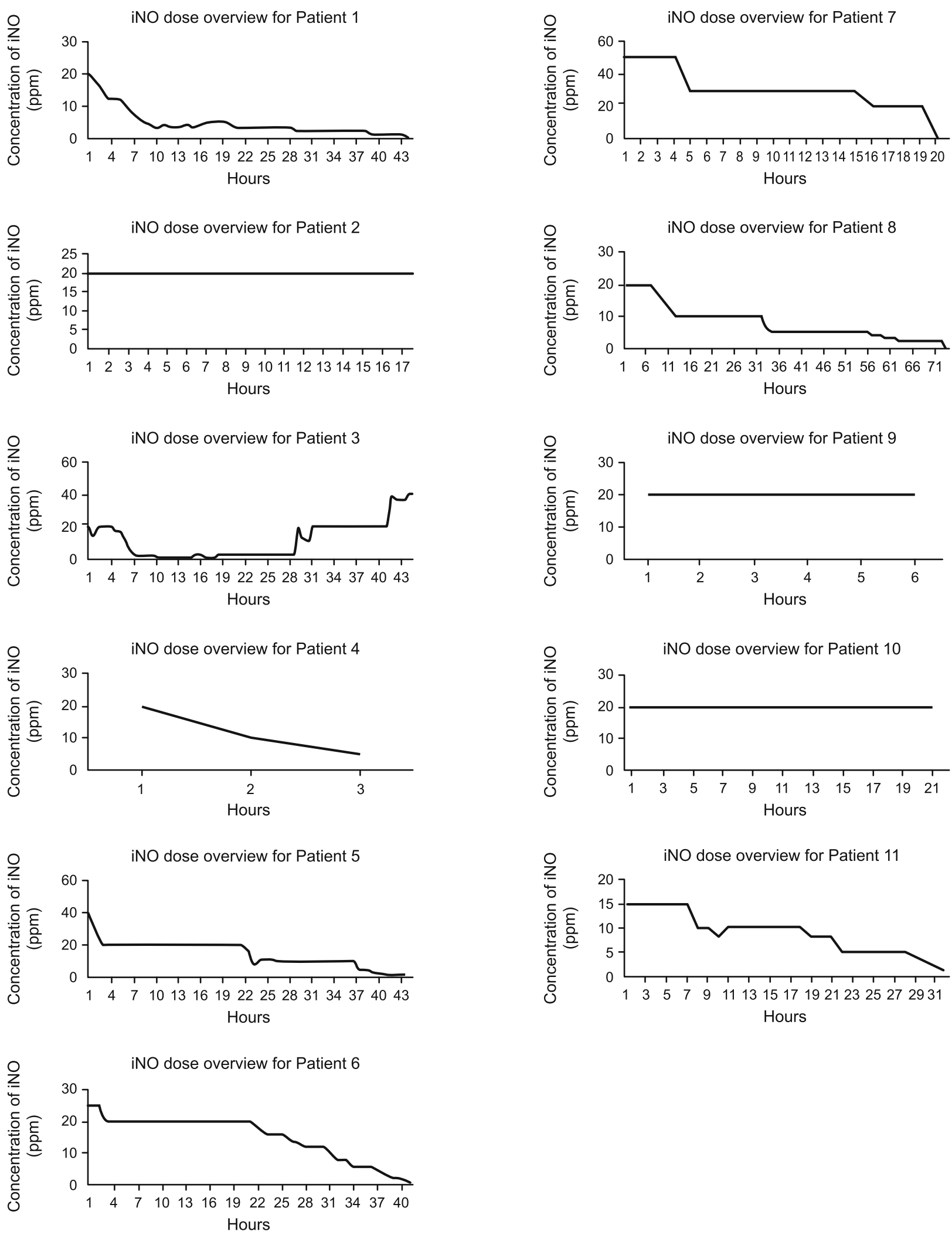

Fig. 1. Graphic representation of therapy course for patients 1-11. iNO - inhaled nitric oxide, ppm - parts per million. 
support was required during therapy in all patients. Dopamine, dobutamine, noradrenaline and adrenaline were used.

Different courses of therapy with iNO in the patients in our study are presented in Figure 1. Patients 1, 5, 6, 8 and 11 display a positive trend in therapy with slow lowering of the doses and gradual weaning off the therapy, which prevents rebound PH. In the case of patient 3 , we can see escalation of the therapy due to the worsening state of the patient. The longest duration of therapy was 95 hours in case of patient 3 and the shortest was 3 hours in case of patient 4 .

\section{Discussion}

At birth, the human lung circulation undergoes a transformation from a high-resistance pulmonary circulation to a low-resistance circulation. In congenital lung diseases and congenital heart defects, this change can be slowed down or stopped. It is important that we are able to quickly and reliably diagnose the increased pressure in the pulmonary circulation and then try to identify the underlying cause of this condition. In the neonatal period, it can be PPHN, which can be caused by meconium aspiration, sepsis or pneumonia, congenital diaphragmatic hernia, congenital heart defects, pulmonary hypoplasia, and structural changes of the airways (34). In our cohort, most patients were diagnosed with secondary PPHN, which was caused by sepsis in one case (Patient 1), pneumonia in two cases (Patients 5 and 6) meconium aspiration in two cases (Patient 9 and 11), and congenital lung developmental defects in two cases (Patients 4 and 8 ).

$\mathrm{PPHN}$ is the cause of respiratory failure in newborns in almost $10 \%$ of the cases. This complex disease can lead to many complications, even death $(10,35)$. Out of the eleven patients in this study, five patients died during the treatment.

Typical symptoms of PPHN are respiratory failure and cyanosis, which occur 6 to 12 hours after birth. It can often manifest as perinatal asphyxia, low Apgar score and amniotic fluid discoloration, but this is not specific. PPHN can occur even without any perinatal manifestations. In our cohort, based on the Apgar score, difficult postnatal adaptation can be seen in up to 9 out of the 11 patients. Amniotic fluid colour changes have been reported in 5 of the patients (27).

Therapy of the newborns with confirmed PPHN consists of supportive therapy aimed at improving systemic haemodynamics. Each patient in our cohort was treated with inotropic agents. In most cases, treatment with two or more substances was required, in one case a combination of up to 4 drugs (Patient 9 received dopamine, dobutamine, adrenaline, noradrenaline) $(22,30)$.

In our cohort, only two patients were born before the 34th week. In a study from 2006 to 2010 , the newborns born before the 34 th week required longer therapy than newborns born in the later gestational weeks. In our cohort, the longest therapy was required by a patient born at 35 weeks (Patient 3 ) and 32 weeks (Patient 8) (95 and 73 hours). Clark attributed these results to more comorbidities in preterm infants compared to full-term infants (36). In our cohort, 4 patients were born prematurely, two of them didn't survive. Although PPHN is more common in term patients, it is important to recognise early signs of preterm labour in mothers and apply adequate prophylaxis because the outcomes and the duration of the treatment are prolonged in preterm infants. There are several promising methods of early diagnosis of preterm labour such as detection of matrix metalloproteinase-8, interleukin- 8 and heat shock protein 70 in vaginal samples of pregnant women in third semester (37).

Our findings regarding the management of childbirth correlate with the results of an American study that documented an increase in the incidence of PPHN syndrome in section-born infants compared to vaginal-born infants. Also, in our cohort, up to 9 children with PPHN requiring iNO therapy were born by section and only 2 vaginally (26).

Abman et al in their chapter mention that changes regarding the amount and colour of amniotic fluid can be associated with PPHN but are not universally applicable as a symptom of PPHN (27). In our cohort, four out of eleven patients had physiologic findings regarding amniotic fluid (Tab. 1). Two of them (Patients 1 and 11) had green stained amniotic fluid. In both cases it was associated with meconium aspiration. Both of these patients recovered, but prolonged therapy with iNO and inotropic agents was needed. Two of these patients (Patient 2 and 4), were diagnosed prenatally with anhydramnion, Patient 4 had prenatally diagnosed polycystic kidney disease which was associated with pulmonary hypoplasia and face anomalies - Potter sequence. Patients 3 and 8 had polyhydramnion diagnosed prenatally. After birth, oesophageal and duodenal atresia was confirmed in the case of patient 3 . In the case of patient 8 , pleural effusion was diagnosed and evacuated prenatally with pulmonary sequestration diagnosed postnatally. Out of 5 patients who died despite intensive therapy only one of them had physiological findings regarding amniotic fluid (Patient 10). Based on our cohort, pathologic findings regarding the amniotic fluid could be a negative prognostic factor in newborns with PPHN because it often indicates associated comorbidities.

The highest dose used in clinical studies was $20 \mathrm{ppm}$. Only in The Neonatal Inhaled Nitric Oxide Study, the dose was increased up to $80 \mathrm{ppm}$, if there was no response to treatment (38). In our cohort, doses from $15 \mathrm{ppm}$ to $40 \mathrm{ppm}$ were administered. The highest dose (40 ppm) was administered to two patients (Patients 3 and 5), one of them (Patient 3) didn't survive and one did (Patient 5). If we look at the gestational age of the patients, patient 3 was born in the 35 th week and patient 5 in week 40 . Patient 3 was born by Caesarean section which is a negative prognostic factor, however, patient 5 was born vaginally (26). The prognosis of the patient could be influenced by the dose, gestational age of the patient and the management of childbirth, although patient 3 also had complex congenital heart disease and atresia of oesophagus and duodenum which could be a risk factor.

The treatment courses for patients in our cohort varied. In graphical representations of treatments of patients 5, 6, 7, 8, and 11 , the typical course of treatment with slow de-escalation of therapy to prevent rebound phenomenon is seen (Fig. 1) $(39,40)$. Out of 11 patients, 7 were given an initial dose of $20 \mathrm{ppm}$. Patient 6 was treated initially with a $25 \mathrm{ppm}$ dose which could be lowered after 3 hours to 20 ppm which was sustained for nearly 20 hours 
and then gradually lowered until the iNO could be discontinued. A similar course of treatment was given to patients 7 and 8 , although each of these patients had different causes of PPHN. Patient 6 was diagnosed with perinatal infection, patient 7 with primary PPHN and patient 8 with pulmonary sequestration. Although diagnosed with primary PPHN, patient 7 received the lowest starting dose (5 ppm) which could be lowered slowly during the course of 20 hours. In the case of patient 1 the de-escalation of treatment was very successful in the first hours which led to a temporary rebound in the $17^{\text {th }}$ hour of therapy which was managed by a slower decrease in iNO concentration. Graph of patients 2, 9, and 10 shows an inadequate response to iNO treatment. All three of these patients died within 21 hours after starting the treatment. Patient 2 and patient 10 were diagnosed with congenital pulmonary malformations which can potentially be the reason for lack of response to treatment. The highest dose (40 ppm) was used in two patients (Patient 3 and 5). Patient 5 received iNO in dose of $40 \mathrm{ppm}$ at the beginning of the treatment which could be perceived as a negative prognostic marker. However, the concentration of iNO could be lowered over the course of 40 hours and the patient could maintain satisfactory saturation of oxygen without iNO. In the case of patient 3 , the highest dose was administered during and after surgery (due to oesophageal atresia and perforation) because the patient didn't tolerate the anaesthesia during the procedure. Based on our cohort, the lower starting dose of iNO is not always associated with better outcomes and there are more factors which influence the outcome such as associated congenital defects of the lungs and heart and need for invasive treatment.

This work had its limitations, such as the lack of anamnestic data in the available documentation. Another limitation is the size of the group of patients, as iNO therapy is used in Slovakia in limited indications, it is not used off-label as in foreign studies. The results of this article could in the future serve as the basis for a study with a larger group of patients, whether prospective or retrospective.

\section{References}

1. Moncada S, Higgs A. The L-Arginine-Nitric Oxide Pathway. N Engl J Med 1993; 329 (27): 2002-2012.

2. Bredt DS, Snyder SH. Nitric oxide, a novel neuronal messenger. Neuron 1992; 8 (1): 3-11.

3. Gaston B, Drazen JM, Loscalzo J, Stamler JS. The biology of nitrogen oxides in the airways. Am J Resp Crit Care Med 1994; 149 (2): 538-551.

4. Jorens PG, Vermeire PA, Herman AG. L-arginine-dependent nitric oxide synthase: A new metabolic pathway in the lung and airways. Eur Respir J 1993; 6 (2): 258-266.

5. Alving K, Weitzberg E, Lundberg JM. Increased amount of nitric oxide in exhaled air of asthmatics. Eur Respir J 1993; 6 (9): 1368-1370.

6. Gustafsson LE, Leone AM, Persson MG, Wiklund NP, Moncada S. Endogenous nitric oxide is present in the exhaled air of rabbits, guinea pigs and humans. Biochem Biophys Res Commun 1991; 181 (2): 852-857.

7. Sokol GM, Konduri GG, Van Meurs KP. Inhaled nitric oxide therapy for pulmonary disorders of the term and preterm infant. Semin Perinatol 2016; 40 (6): 356-369.
8. Dewhurst C, Harigopal S, Subhedar N. Recent advances in inhaled nitric oxide therapy in neonates: A review of the evidence. Infant 2007; 3 (2): 69-75.

9. Kinsella JP, Abman SH. Clinical approach to inhaled nitric oxide therapy in newborn with hypoxemia. J Pediatr 2000; 136 (6): 717-726.

10. Storme L, Aubry E, Rakza T, Houeijeh A, Debarge V, Tourneux P, Deruelle P, Pennaforte T. Pathophysiology of persistent pulmonary hypertension of the newborn: Impact of the perinatal environment. Arch Cardiovasc Dis 2013; 106 (3): 169-177.

11. Sharma V, Berkelhamer S, Lakshminrusimha S. Persistent pulmonary hypertension of the newborn. Matern Health Neonatol Perinatol 2015; 1 (14).

12. Abman SH, Groothius JR. Pathophysiology and treatment of bronchopulmonary dysplasia: Current issues. Pediatr Clin North Am 1994; 41 (2): 277-315.

13. Kinsella JP, Neish SR, Shaffer E, Abman SH. Low-dose inhalational nitric oxide in persistent pulmonary hypertension of the newborn. Lancet 1992; 340 (8823): 819-820.

14. Kinsella JP. Inhaled nitric oxide in the term newborn. Early Hum Dev 2008; 84 (11): 709-716.

15. European Medicine Agency. INOmax: EPAR- Product Information [online]. 2009. [cited 21-4-2021]. Available: https://www.ema.europa. eu/documents /product-information/inomax-epar-product-information sk.pdf.

16. Matthews DC, Glader B. Erythrocyte Disorders in Infancy. Avery's Diseases of the Newborn (Ninth Edition) 2012: 1080-1107.

17. Weinberger B, Laskin DL, Heck DE, Laskin JD. The toxicology of inhaled nitric oxide. Toxicol Sci 2001; 59: 5-16.

18. Coleman MD, Coleman NA. Drug-Induced Methaemoglobinaemia Treatment Issues. Drug Saf 1996; 14 (6): 394-405.

19. Abernethy C. Nitric oxide therapy in the neonate: guideline for the use of inhaled nitric oxide [online]. NHSGGC Paediatrics for Health Professionals. 2021. [cited 21-4-2021] Available: https://www.clinicalguidelines.scot.nhs.uk/nhsggc-paediatric-clinical-guidelines/nhsggc-guidelines/ neonatology/nitric-oxide-therapy-in-the-neonate-guideline-for-the-use-ofinhaled-nitric-oxide.

20. Kiserud T. Physiology of the fetal circulation. Semin Fetal Neonatal Med 2005; 10 (6): 493-503.

21. Steinhorn RH, Kinsella JP, Pierce C, Butrous G, Dilleen M, Oakes M, Wessel DL. Intravenous Sildenafil in the Treatment of Neonates with Persistent Pulmonary Hypertension. J Pediatr 2009; 155 (6): 841-847.

22. Lakshminrusimha S, Keszler M. Persistent Pulmonary Hypertension of the Newborn. Neoreviews 2015; 16 (12): 680-692.

23. Delaney C, Cornfield DN. Risk Factors for Persistent Pulmonary Hypertension of the Newborn. Pulm Circ 2012; 2 (1): 15-20.

24. Langham MR, Kays DW, Ledbetter D J, Frentzen B, Sanford LL, Richards DS. Congenital Diaphragmatic Hernia: Epidemiology and Outcome. Clin Perinatol 1996; 23 (4): 671-688.

25. Kunochova I, Krizko M, Papcun P, Gabor M, Alfoldi M, Feriancova M, Ferianec V. Routine betamethasone therapy of non-hydropic fetuses with CPAM - the way to improve perinatal outcome? Bratisl Med J 2021; 122 (9) 657- 662

26. Wilson KL, Zelig CM, Harvey JP, Cunningham BS, Dolinsky BM, Napolitano PG. Persistent pulmonary hypertension of the newborn is as- 
sociated with mode of delivery and not with maternal use of selective serotonin reuptake inhibitors. Am J Perinatol 2011; 28 (1): 19-24.

27. Abman SH, Steinhorn RH, Aschner JL. Persistent Pulmonary Hypertension of the Newborn: Mechanisms and Treatment. Textbook of Pulmonary Vascular Disease 2010: 1109-1118.

28. Manja V, Mathew B, Carrion V, Lakshminrusimha S. Critical congenital heart disease screening by pulse oximetry in a neonatal intensive care unit. J Perinatol 2015; 35 (1): 67-71.

29. Patterson K, Kapur SP, Chandra RS. PPHN: pulmonary pathologic effects. In Rosenberg HS, Bernstein J (eds): Cardiovascular Diseases, Perspectives in Pediatric Pathology 1988; 12: 139-154.

30. UK ECMO Trial Group. UK collaborative randomised trial of neonatal extracorporeal membrane oxygenation. Lancet 1996; 348 (9020): 75-82.

31. Clark RH, Kueser TJ, Walker MW, Southgate WM, Huckaby JL, Perez JA, Roy BJ, Keszler M, Kinsella JP. Low-dose nitric oxide therapy for persistent pulmonary hypertension of the newborn. Clinical Inhaled Nitric Oxide Research Group. N Engl J Med 2000; 342 (7): 469474.

32. Nair J, Lakshminrusimha S. Update on PPHN: mechanisms and treatment. Semin Perinatol 2014; 38 (2): 78-91.

33. Baquero H, Soliz A, Neira F, Venegas ME, Sola A. Oral Sildenafil in Infants With Persistent Pulmonary Hypertension of the Newborn: A Pilot Randomized Blinded Study. Pediatrics 2006; 117 (4): 1077-1083.
34. Aschner JL, Fike CD, Austin ED, Barr FE, Donald MJ. Pediatric Pulmonary Hypertension: An Integrated View from Pediatric Subspecialists. Textbook of Pulmonary Vascular Disease 2010: 1083-1108.

35. Kinsella JP, Abman SH. Medical progress. Recent developments in the pathophysiology and treatment of persistent pulmonary hypertension of the newborn. J Pediatr 1995; 126 (6): 853-864.

36. Clark RH, Ursprung RL, Walker MW, Ellsbury DL, Spitzer AR. The changing pattern of inhaled nitric oxide use in the neonatal intensive care unit. J Perinatol 2010; 30 (12): 800-804.

37. Sisti G, Paccosi S, Parenti A, Seravalli V, Linari C, Di Tommaso M, Witkin S. Pro-inflammatory mediators in vaginal fluid and short cervical length in pregnancy. Bratisl Med J 2020; 121 (4): 278-281.

38. The Neonatal Inhaled Nitric Oxide Study Group. Inhaled Nitric Oxide in Full-Term and Nearly Full-Term Infants with Hypoxic Respiratory Failure. N Engl J Med 1997; 336 (9): 597-604.

39. Sokol GM, Fineberg NS, Wright LL, Ehrenkranz RA. Changes in arterial oxygen tension when weaning neonates from inhaled nitric oxide. Pediatr Pulmonol 2001; 32 (1): 14-19.

40. Srnkova P. Nitric oxid in diagnostics and therapy of the diseases of neonatal age. Diploma thesis. Comenius University in Bratislava. Faculty of Medicine. 2020; 89 p. 